\title{
ANALYSIS OF MULTIPLE BIRTHS IN JAPAN
}

\section{ANALYSIS OF FACTORS AFFECTING BIRTH WEIGHT OF TWINS AND TRIPLETS}

\author{
Akio AsAKa, ${ }^{1}$ Yoko ImaIzUmI, ${ }^{2}$ and Eiji INOUYE ${ }^{1}$ \\ ${ }^{1}$ Institute of Brain Research, University of Tokyo School of Medicine, \\ Tokyo 113, Japan \\ ${ }^{2}$ Institute of Population Problems, Ministry of Health and Welfare, \\ Tokyo 100, Japan
}

\begin{abstract}
Summary Analysis of factors affecting birth weight among twins and triplets was performed. The total weight of the twins and triplets was increased with gestational age. Maternal age and birth order at the twin births had a close relationship with birth weight, and higher total weights were seen mostly in the middle of mother's age groups between 25 and 29 or 30 and 34 years in every birth order. The total weight of the twins was the highest in the household, occupation of the head of which was "agriculture only." Seasonal variations of birth weight were observed and higher ones were seen in the twins born in March and September. The total birth weight was lower in the twins born to mothers who have previously experienced stillbirth before fifth months of pregnancy.
\end{abstract}

The present study aims at clarifying the effect of factors such as gestational age, maternal age, order of the births and others on birth weight of multiple births in Japan.

\section{DATA AND METHODS}

Data are similar to those which were previously reported in relation to survival states, sex, birth order within the sets, and zygosity (Asaka et al., 1980a, 1980b). After totaling the members' birth weights of the twins or the triplets of all births, the total weight was analysed according to classes in each items mentioned below by analysis of variance. There are 13 items listed in "Survey A," which includes four items regarding birth place:

[1] Forty-seven prefectures

[2] Nine districts, which were made up from above prefectures

[3] Two areas; (1) urban and (2) rural 
[4] Kinds of place where the twins or the triplets were born; (1) hospital (2) general clinic (3) maternity clinic (4) mother's home and (5) others Other items are:

[5] Persons who assisted the mother in the twins' or the triplets' delivery; (1) doctor (2) midwife and (3) others

[6] Occupation of the head of the household; (1) agriculture only (2) agriculture with other works (3) self employed (4) white collar (5) blue collar and (6) others

[7] Months of the twins or the triplets births; from January to December

[8] Months of the conceptions of the twins or the triplets; from January to December

[9] Number of stillborn children after sixth months of pregnancy among sibs excluding the twins or the triplets

[10] Number of stillborn children before fifth months of pregnancy among sibs excluding the twins or the triplets

[11] Gestational age in month of the twins or the triplets

[12] Order of the birth of the twins or the triplets in the sibship

[13] Maternal age at the birth of the twins or the triplets, which was divided into six groups; (1) 19 or less (2) 20 to 24 (3) 25 to 29 (4) 30 to 34 (5) 35 to 39 and (6) 40 or more years of age.

\section{RESULTS}

Among sets of twins significant differences of the total weight were obtained in the following six items in twins: (1) gestational age at the twin births, (2) maternal age at the twin births, (3) order of the twin births in the sibship, (4) occupation of the head of the household, (5) month of the twin births and (6) number of stillbirths before fifth months of pregnancy among sibs of the twins. An additional significant result was obtained in: (7) gestational age of the triplet births. The results are listed in Table 1. In this Table tables of analysis of variance are omitted for the brevity, and only $F$ values are shown.

As shown in Table 1, the total weight increased with gestational age from 7 to 11 months, and the similar tendency was seen in triplets as in (7) in Table 1. As for maternal age mean of the total weight was gradually increased from the groups of maternal age below 19 years to those between 30 and 34 years, and was decreased thereafter until those of 40 years or over. Mean of the total weight increased from the first to the third birth order and decreased thereafter. With respect to the occupation of the head of the household, the highest mean total weight was seen in "agriculture only" and the lowest in "others." It was higher in "white collar" than in "blue coller." A bimodality of mean total weight was seen in twins in March and September, the former being higher than the latter, and it was lowest in 
Table 1. Significant difference of the mean total birth weight $(\mathrm{g})$ in twins and triplets.

\begin{tabular}{lrrrr} 
& \multicolumn{1}{c}{$\begin{array}{c}\text { Number of } \\
\text { twin sets }\end{array}$} & Mean & $\begin{array}{c}\text { Standard } \\
\text { deviation }\end{array}$ & F values \\
\hline (1) $\begin{array}{l}\text { Gestational age at the twin births } \\
49\end{array}$ & 2,016 & 821 & \\
7 months & 546 & 2,617 & 681 & $F(4,11,263)=2,300.5$ \\
8 months & 1,847 & 3,895 & 660 & $\mathrm{p}<0.001$ \\
9 months & 8,742 & 4,998 & 730 & \\
10 months & 84 & 5,346 & 692 & \\
11 months & 11,268 & 4,692 & 966 &
\end{tabular}

(2) Maternal age at the twin births

\begin{tabular}{rrrrl}
-19 & 72 & 4,349 & 961 & \\
$20-24$ & 2,831 & 4,566 & 973 & \\
$25-29$ & 5,598 & 4,724 & 950 & $F(5,11,264)=19.4$ \\
$30-34$ & 2,258 & 4,792 & 968 & $\mathrm{p}<0.005$ \\
$35-39$ & 451 & 4,679 & 1,003 & \\
$40-$ & 60 & 4,323 & 1,086 & \\
\hline Total & 11,270 & 4,692 & 966 \\
\hline
\end{tabular}

(3) Order of the twin births

\begin{tabular}{lrrrl}
1 & 4,957 & 4,554 & 924 & \\
2 & 3,974 & 4,805 & 939 & \\
3 & 1,513 & 4,844 & 1,037 & $F(5,10,821)=45.3$ \\
4 & 282 & 4,762 & 1,198 & $\mathrm{p}<0.005$ \\
5 & 58 & 4,647 & 1,160 & \\
$6-$ & 43 & 3,926 & 1,325 & \\
\hline Total & 10,827 & 4,690 & 967 & \\
\hline
\end{tabular}

(4) Occupation of the head of the household

$\begin{array}{lrrrr}\text { Agriculture only } & 405 & 4,789 & 956 & \\ \text { Agric. w. other works } & 759 & 4,679 & 965 & \\ \text { Self employed } & 1,396 & 4,704 & 989 & \\ \text { White collar } & 4,257 & 4,711 & 968 & \mathrm{~F}(5,11,236)=2.5 \\ \text { Blue collar } & 3,619 & 4,674 & 943 & \mathrm{p}<0.05 \\ \text { Others } & 806 & 4,617 & 1,015 & \\ \text { Total } & 11,242 & 4,692 & 966 & \end{array}$

Vol. 25, No. 3, 1980 
Table 1. (Continued)

(5) Months of the twin births

$\begin{array}{lrrrr}\text { January } & 959 & 4,649 & 925 & \\ \text { February } & 949 & 4,729 & 925 & \\ \text { March } & 913 & 4,766 & 944 & \\ \text { April } & 895 & 4,697 & 958 & \\ \text { May } & 908 & 4,689 & 974 & \mathrm{~F}(11,11,259)=1.9 \\ \text { June } & 914 & 4,646 & 1,040 & \mathrm{p}<0.05 \\ \text { July } & 998 & 4,662 & 951 & \\ \text { August } & 978 & 4,717 & 946 & \\ \text { September } & 952 & 4,739 & 961 & \\ \text { October } & 961 & 4,709 & 966 & \\ \text { November } & 907 & 4,683 & 1,042 & \\ \text { December } & 937 & 4,619 & 958 & \\ \text { Total } & 11,271 & 4,692 & 966 & \end{array}$

(6) Number of stillbirths before fifth months of pregnancy among sibs

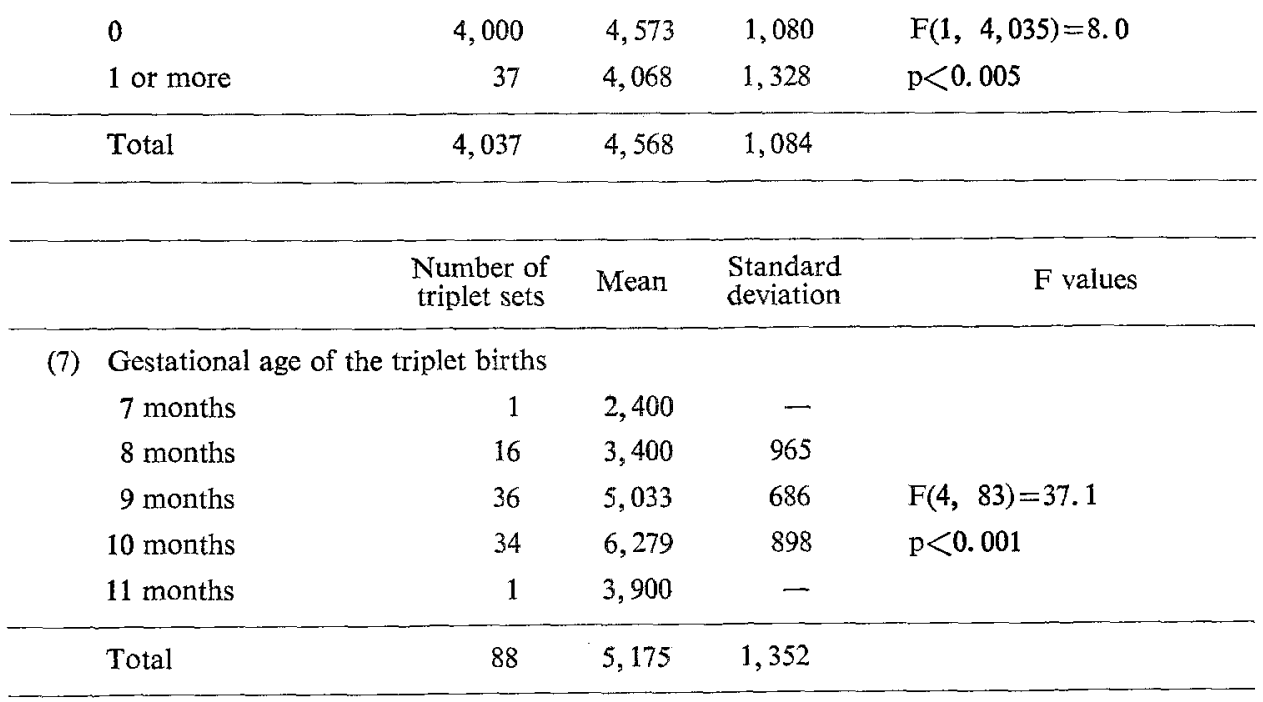

December. The mean was lower in those who had stillbirths before fifth months of pregnancy among sibs than in those who did not.

The maternal age and the birth order are expected to be closely correlated with each other, and in fact the correlation coefficient is $0.4391(\mathrm{p}<0.001, \mathrm{n}=$ $11,773)$ in the present sample. On the other hand, the correlation coefficient between the maternal age and the gestational age is $-0.0121(p>0.09, n=12,244)$. Therefore, the total birth weight was broken down by the maternal age and the 
Table 2. Mean of the total birth weight (g) of twins according to maternal age and birth order.

\begin{tabular}{|c|c|c|c|c|c|c|c|}
\hline \multirow{2}{*}{$\begin{array}{c}\text { Maternal } \\
\text { age (years) }\end{array}$} & \multicolumn{7}{|c|}{ Birth order } \\
\hline & 1 & 2 & 3 & 4 & 5 & $6-$ & Total \\
\hline-19 & $\left(\begin{array}{c}4,415 \\
59)\end{array}\right.$ & $\left(\begin{array}{c}3,850 \\
8\end{array}\right)$ & $\left(\begin{array}{r}5,400 \\
1\end{array}\right)$ & - & - & - & $\left(\begin{array}{r}4,363 \\
68\end{array}\right)$ \\
\hline $20-24$ & $\begin{array}{c}4,533 \\
(1,939)\end{array}$ & $\begin{array}{c}4,690 \\
\left(\begin{array}{l}675 \\
)\end{array}\right)\end{array}$ & $\left.\begin{array}{c}4,494 \\
95\end{array}\right)$ & $\left(\begin{array}{r}4,030 \\
13\end{array}\right)$ & $\left(\begin{array}{r}4,200 \\
3\end{array}\right)$ & $\left(\begin{array}{r}3,900 \\
2\end{array}\right)$ & $\begin{array}{c}4,567 \\
(2,727)\end{array}$ \\
\hline $25-29$ & $\begin{array}{c}4,577 \\
(2,385)\end{array}$ & $\begin{array}{c}4,855 \\
(2,300)\end{array}$ & $\begin{array}{c}4,841 \\
\left(\begin{array}{c}610\end{array}\right)\end{array}$ & $\left(\begin{array}{r}4,579 \\
82)\end{array}\right)$ & $\begin{array}{c}4,583 \\
\left(\begin{array}{r}12 \\
)\end{array}\right)\end{array}$ & $\left(\begin{array}{r}3,080 \\
5\end{array}\right)$ & $\begin{array}{c}4,724 \\
(5,394)\end{array}$ \\
\hline $30-34$ & $\begin{array}{c}4,576 \\
(482)\end{array}$ & $\left(\begin{array}{c}4,794 \\
\left(\begin{array}{r}852 \\
)\end{array}\right)\end{array}\right.$ & $\begin{array}{c}4,911 \\
(\quad 666)\end{array}$ & $\begin{array}{c}4,959 \\
\left(\begin{array}{l}127 \\
127\end{array}\right)\end{array}$ & $\left(\begin{array}{r}4,796 \\
25)\end{array}\right.$ & $\left(\begin{array}{r}3,433 \\
9\end{array}\right)$ & $\begin{array}{r}4,785 \\
(2,161)\end{array}$ \\
\hline $35-39$ & $\left(\begin{array}{c}4,411 \\
81\end{array}\right)$ & $\left(\begin{array}{c}4,731 \\
126\end{array}\right)$ & $\begin{array}{c}4,792 \\
\left(\begin{array}{l}130 \\
)\end{array}\right)\end{array}$ & $\left(\begin{array}{c}4,802 \\
50)\end{array}\right.$ & $\left.\begin{array}{c}4,544 \\
16\end{array}\right)$ & $\begin{array}{c}4,176 \\
17)\end{array}$ & $\left.\begin{array}{c}4,667 \\
420\end{array}\right)$ \\
\hline $40-$ & $\left(\begin{array}{c}4,173 \\
11\end{array}\right)$ & $\left(\begin{array}{r}4,008 \\
12\end{array}\right)$ & $\left(\begin{array}{r}4,681 \\
11)\end{array}\right.$ & $\left(\begin{array}{r}4,520 \\
10\end{array}\right)$ & $\left(\begin{array}{r}4,650 \\
2\end{array}\right)$ & $\left(\begin{array}{r}4,370 \\
10\end{array}\right)$ & $\left(\begin{array}{r}4,352 \\
56)\end{array}\right.$ \\
\hline Total & $\begin{array}{c}4,554 \\
(4,957)\end{array}$ & $\begin{array}{c}4,805 \\
(3,973)\end{array}$ & $\begin{array}{c}4,844 \\
(1,513)\end{array}$ & $\begin{array}{c}4,762 \\
\left(\begin{array}{l}282 \\
)\end{array}\right)\end{array}$ & $\left(\begin{array}{c}4,647 \\
58)\end{array}\right.$ & $\begin{array}{c}3,926 \\
(43)\end{array}$ & $\begin{array}{r}4,690 \\
(10,826)\end{array}$ \\
\hline
\end{tabular}

Note: Number in parenthesis indicates the number of sets of twins.

birth order. The result is shown in Table 2. Excluding the class of birth order of sixth or more, a clear tendency was seen in that in every birth order of the twin births mean of the total weight was the highest in the middle of the maternal age groups between 25 and 29 or 30 and 34 years.

\section{DISCUSSION}

It was indicated that mean of the total birth weight was increased with gestational age. Karn (1952a, 1952b, 1953) observed high correlation between birth weight and gestational age among twins, and Pettersson et al. (1976) also mentioned the similar features. Both reports are in agreement with ours.

Higher mean total birth weights were seen mostly in the middle of maternal age groups between 25 and 29 or 30 and 34 years in every birth order of the twin births. McKeown and Record (1952) and Bleker et al. (1979) have found higher birth weight of twins in multiparae than in primiparae. Karn (1952a, 1952b, 1953) reported that the birth weight of twins was rather correlated with parity than with mother's age, which she regarded as non-effective on birth weight. However, number of data she examined seems to be not so large enough to draw such a conclusion. Parsons (1964) has shown that the lowest birth weight of twins was seen in the first order, and that from the second pregnancy onwards there was a slow increase in birth weight. In his data, the influence of maternal age was far less clear-cut, and he attributed the result to a small sample size.

It was seen that mean of the total birth weight differed according to the occu- 
pation of the head of the household, suggesting the presence of environmental factors which influence the birth weight of twin pregnancy. Howard and Brown (1970), using socioeconomic scores (SES) as one of parameters, compared the difference of SES among races, sex compositions and fetal presentations, but direct association between birth weight of twins and SES was not described. However, in comparison of breech and cephalic presentations, birth weight as well as SES rating was higher in the latter, suggesting a relation between birth weight and socioeconomic status.

Higher birth weights were seen in twin deliveries in March and September, and the lowest in December. Mild or severe climate may affect the birth weight of twins, though no reports on seasonal variations are available in the literature.

It was shown that lower birth weight was seen in mothers who experienced spontaneous abortions before fifth months of pregnancy among sibs. It is thus suggested that there are some maternal dispositions which influence birth weight, though exogeneous factors cannot be excluded.

This study was supported in part by the Grant Aided by the Ministry of Health and Welfare of Japan for the Handicapped Children, 1979.

\section{REFERENCES}

Asaka, A., Imaizumi, Y., and Inouye, E. 1980a. Analysis of multiple births in Japan. I. Weight at birth among 12,392 pairs of twins. Jpn. J. Human Genet. 25: 65-71.

Asaka, A., Imaizumi, Y., and Inouye, E. 1980b. Analysis of multiple births in Japan. II. Weight at birth of triplets and quadruplets. Jpn. J. Human Genet. 25: 207-211.

Bleker, O.P., Breur, W., and Huidekoper, B.L. 1979. A study of birth weight, placental weight and mortality of twins as compared to singletons. Brit. J. Obst. Gyn. 86: 111-118.

Howard, R., and Brown, A.M. 1970. Twinning: a marker for biological insults. Child Dev. 41: 519-530.

Karn, M.N. 1952a. Birth weight and length of gestation of twins, together with maternal age, parity and survival rate. Ann. Eugen. 16: 365-377.

Karn, M.N. 1952b. Twin data: a further study of birth weight, gestation time, maternal age, order of birth, and survival. Ann. Eugen. 17: 233-248.

Karn, M.N. 1953. Data of twin births occurring in 2 English metropolitan hospitals. Acta Genet. Med. Gemello. 2: 152-163.

McKeown, T., and Record, R.G. 1952. Observations on foetal growth in multiple pregnancy in man. J. Endocr. 8: 386-401.

Parsons, P.A. 1964. Birth weights and survival of unlike-sexed twins. Ann. Hum. Genet. 28: 1-10.

Pettersson, F., Smedby, B., and Lindmark, G. 1976. Outcome of twin birth. Review of 1636 children born in twin birth. Acta Paediat. Scand. 65: 473-479. 